\title{
Antipsychotic prescription patterns and treatment costs of schizophrenia in northwestern Pakistan: A one-year observational study
}

\author{
Abuzar Khan ${ }^{1}$, Zafar Iqbal ${ }^{1 *}$, Syed M Sultan ${ }^{2}$, Zahid Nazar $^{3}$, Muhammad Tariq $^{4}$ \\ ${ }^{1}$ Department of Pharmacy, University of Peshawar, ${ }^{2}$ Department of Psychiatry, Khyber Teaching Hospital, ${ }^{3}$ Department of \\ Psychiatry, Lady Reading Hospital, ${ }^{4}$ Sarhad Hospital for Psychiatric Diseases, Peshawar, Pakistan
}

*For correspondence: Email: zafar_iqbal@uop.edu.pk; Tel: 0092-3339228402

Sent for review: 16 September 2017

Revised accepted: 18 January 2018

\begin{abstract}
Purpose: To evaluate the antipsychotic drugs most commonly prescribed for schizophrenia patients in Peshawar, Pakistan and to analyze the treatment costs associated with these drugs.

Methods: One hundred patients diagnosed with schizophrenia were recruited from outpatient psychiatry departments in Peshawar, Pakistan and followed for one year. Demographic data were collected for each patient at the beginning of the study. A questionnaire was used to collect antipsychotic prescription information at 4, 8 and 12 months. The cost of antipsychotics was obtained from PharmaGuide, Pakistan. The cost associated with antipsychotic drug use was statistically analyzed using post hoc tests.

Results: Of the patients who completed this study, $68.1 \%$ were prescribed second-generation antipsychotic (SGA) drugs, $6.9 \%$ first-generation antipsychotic (FGA) drugs, and $25.0 \%$ a combination of SGAs and FGAs. Furthermore, $40.3 \%$ of the patients who completed the study received antipsychotic monotherapy and $34.7 \%$ antipsychotic polytherapy. In monotherapy, risperidone was the most commonly prescribed antipsychotic drug, used by $44.8 \%$ of patients while in polytherapy, risperidone plus olanzapine was the most commonly prescribed combination, used by $32 \%$ of patients. Switching of antipsychotic drugs was observed in $25 \%$ of patients. The mean annual cost of antipsychotic therapy was US\$79.90 (8079 Pakistani rupees). Risperidone treatment cost was US\$60.30 (PakRs 6095), constituting $52 \%$ of the total monotherapy cost. The cost of SGAs was significantly higher than the cost of FGAs $(p<0.05)$.

Conclusion: The results provide policymakers with appropriate information necessary for managing pharmacotherapy plans for the treatment of schizophrenia.
\end{abstract}

Keywords: Schizophrenia, Prescribing pattern, Antipsychotics, Cost analysis, Pharmacotherapy

\begin{abstract}
This is an Open Access article that uses a funding model which does not charge readers or their institutions for access and distributed under the terms of the Creative Commons Attribution License (http://creativecommons.org/licenses/by/4.0) and the Budapest Open Access Initiative (http://www.budapestopenaccessinitiative.org/read), which permit unrestricted use, distribution, and reproduction in any medium, provided the original work is properly credited.

Tropical Journal of Pharmaceutical Research is indexed by Science Citation Index (SciSearch), Scopus, International Pharmaceutical Abstract, Chemical Abstracts, Embase, Index Copernicus, EBSCO, African Index Medicus, JournalSeek, Journal Citation Reports/Science Edition, Directory of Open Access Journals (DOAJ), African Journal Online, Bioline International, Open-J-Gate and Pharmacy Abstracts
\end{abstract}

\section{INTRODUCTION}

Schizophrenia is a severe mental disorder that affects the patient's perceptions, language, behavior, and thinking [1]. A prolonged course of therapy is required to treat this disease, which can impose a significant financial burden on the patient and their family $[2,3]$. This is especially 
true in low and middle income countries that lack treatment facilities such as nursing homes and community rehabilitation centers $[4,5]$.

Antipsychotic drugs account for much of the cost of schizophrenia treatment. The older, firstgeneration antipsychotic (FGA) drugs are efficacious in treating the positive symptoms of schizophrenia and are relatively inexpensive. However, these drugs can cause serious side effects, such as extrapyramidal symptoms and tardive dyskinesia, which can lead to irreversible damage and non-compliance by the patient $[1,6]$. The newer, second-generation antipsychotic (SGA) drugs cause fewer side effects, are helpful in reducing the negative symptoms of schizophrenia, and are well tolerated by patients [7] but are costly compared to FGAs [8]. Schizophrenia may be treated with a single drug or a drug combination [9,10]. FGAs and SGAs are commonly co-prescribed [10], and this combination therapy has been shown to be effective in the treatment of acute psychotic symptoms.

Antipsychotic drugs may be administered orally or via long-acting antipsychotic injection (LAI). LAls have been shown to help prevent relapse and reduce hospitalizations $[9,11]$ and are particularly useful in the $50-60 \%$ of schizophrenic patients who are noncompliant $[12,13]$. Combined oral administration of SGAs and LAI administration of FGAs has been shown to be particularly effective $[13,14]$.

Variations in the prescribing pattern of antipsychotics exists among different countries due to factors including drug availability, efficacy, adverse effects, cost, and local prescription guidelines [15]. To date, no detailed study regarding antipsychotic use and its associated cost has been conducted in Pakistan. Therefore, this study will provide new insight into the antipsychotic prescribing practices in Pakistan and the costs associated with the use of antipsychotic drugs.

\section{METHODS}

This descriptive study was conducted in three major hospitals in the city of Peshawar, Khyber Pakhtun Khwa, Pakistan: the Sarhad Hospital for Psychiatric Diseases, Khyber Teaching Hospital, and Lady Reading Hospital. The study was approved by the ethical committee of Khyber Medical College, Peshawar (ref no. 19/RD/Cell/KMC) and was conducted in accordance with the 1964 Helsinki declaration. Informed consent to participate in the study was obtained from all patients, and patient data were coded for confidentiality [16].

Using a convenience sampling method, 100 patients were recruited into this study between July 2014 and June 2015. This sample size, calculated using the World Health Organization sample size calculator, takes into account the high dropout rate expected to occur over the 1year course of the study [17]. All patients included in the study were between 18 and 80 years old, had a diagnosis of schizophrenia (ICD10 in the World Health Organization International Statistical Classification of Diseases and Related Health Problems classification system), and had at least one attendant. Patients with a co-morbid illness or with demographic data that were not credible were excluded from the study sample. As electronic patient medical records were not available in all of the selected hospitals, a questionnaire was developed to collect sociodemographic information and to record prescriptions of antipsychotics and other drugs. Patients and attendants were required to keep complete medical records during the 1-year course of the study and to complete the questionnaire at 4, 8 and 12 months, for a total of three assessments. Drug prices were obtained from Pharma-Guide Pakistan.

\section{Data analysis}

Patients were placed in three groups depending on the antipsychotic treatment regimen they received. Patients in Group I received antipsychotic monotherapy for the entire year. Patients in Group II received antipsychotic polytherapy. Patients in Group III switched from one treatment regimen to another during the course of the year.

The type of antipsychotic drug or drug combination prescribed for each patient was assessed. Within each group, the number of patients receiving a particular type of antipsychotic treatment was measured, and the percentage of patients receiving that treatment was calculated based on the total number of patients in that group. The annual antipsychotic cost was calculated as the mean cost per day multiplied by the number of days the antipsychotic was used. Statistical Package for Social Sciences (SPSS version 20, Chicago ILUSA) software was used calculates the mean annual antipsychotic prescription drug cost for all patients receiving a particular type of therapy using one-way ANOVA (post hoc analysis). For this study, a $p$-value of $\leq 0.05$ was considered statistically significant. 


\section{RESULTS}

\section{Demographic and clinical variables}

Twenty-eight patients failed to return for followup appointments and were excluded from the study, leaving 72 patients in the final study population. Demographic and clinical variables for patients in the final study population are shown in Table 1. In the final population, $67.7 \%$ of patients were male. The majority of patients $(63.9 \%)$ were young adults between 18 and 38 years of age. More than half of the patients (54.2 $\%)$ were married, and most $(62.5 \%)$ were educated. At the time of enrollment in the study, the mean duration of illness was 2.8 years, and the mean positive and negative syndrome scale score was 77.6.

Table 1: Demographic and clinical variables $(N=72)$

\begin{tabular}{lc}
\hline Variable & $\mathbf{N}(\%)$ \\
\hline Sex & $24(33.3)$ \\
Female & $48(67.7)$ \\
Male & \\
Age, years & $46(63.9)$ \\
$18-38$ & $24(33.3)$ \\
$39-59$ & $2(2.8)$ \\
$60-80$ & $33.6 \pm 11$ \\
Mean \pm SD & \\
Marital status & $33(45.8)$ \\
Unmarried & $39(54.2)$ \\
Married & \\
Education & $27(37.5)$ \\
Uneducated & $45(62.5)$ \\
Educated & $2.8 \pm 1.3$ \\
Duration of illness, & \\
years (mean $\pm S D)$ & $29(40.3)$ \\
Monotherapy & $25(34.7)$ \\
Polytherapy & $18(25)$ \\
Switching of & \\
Antipsychotics & \\
Antipsychotic Type & \\
SGA & $49(68.1)$ \\
FGA & $5(6.9)$ \\
SGA + FGA & $18(25.0)$ \\
\hline
\end{tabular}

A slight majority of patients $(40.3 \%)$ received monotherapy. The remaining patients $(34.7 \%)$ received polytherapy. SGAs alone were prescribed to $68.1 \%$ of patients, FGAs alone were prescribed to $6.9 \%$ of patients, and a combination of SGAs and FGA was prescribed to $25 \%$ of patients.

\section{Drug prescription patterns and associated costs}

The mean number of antipsychotics prescribed per patient was 1.4. Among the three study centers participating in this study, Khyber Teaching Hospital prescribed the lowest number of antipsychotics per patient (1.07). Lady Reading Hospital prescribed an average of 1.3 antipsychotics per patient, and Sarhad Hospital for Psychiatric Diseases prescribed 1.8 antipsychotics per patient.

Table 2 shows the drug prescription pattern and average annual drug cost for patients receiving antipsychotic monotherapy (Group I). This group represents $40.3 \%$ of the population. In this group, risperidone was the most commonly prescribed antipsychotic, used by $44.8 \%$ of patients. The remaining patients were prescribed olanzapine $(34.5 \%)$, aripiprazole (10.3\%), haloperidol $(6.9 \%)$, and prochlorperazine (3.4 $\%$ ). The mean cost of antipsychotic monotherapy was \$ 52 USD (Rs. 5255). Risperidone treatment was the most expensive, costing \$ 60.30 USD (Rs. 6095) and constituting $52 \%$ of the total monotherapy cost. Olanzapine treatment was the second most expensive, costing \$ 59.70 USD (Rs. 6039).

Table 2: Type of antipsychotic used and annual drug cost for patients in Group I

\begin{tabular}{|c|c|c|c|}
\hline Antipsychotic & n (\%) & $\begin{array}{c}\text { Average } \\
\text { annual } \\
\text { costc }^{\mathrm{c}} \\
\text { (US\$, } \\
\text { mean } \pm \\
\text { SD) }\end{array}$ & $\begin{array}{c}\text { Annual } \\
\text { cost } \\
(\%)\end{array}$ \\
\hline \multicolumn{4}{|l|}{$\begin{array}{l}\text { Single } \\
\text { antipsychotic }\end{array}$} \\
\hline Risperidone & $\begin{array}{c}13 \\
(44.8)\end{array}$ & $60.3 \pm 32$ & 52.0 \\
\hline Olanzapine & $\begin{array}{c}10 \\
(34.5)\end{array}$ & $59.7 \pm 34$ & 39.6 \\
\hline Aripiprazole & $3(10.3)$ & $29.2 \pm 7.1$ & 5.8 \\
\hline Haloperidol & $\begin{array}{l}2(6.9) \\
1(3.4)\end{array}$ & $\begin{array}{c}15 \pm 3.3 \\
8.4\end{array}$ & $\begin{array}{l}2.0 \\
0.6\end{array}$ \\
\hline \multicolumn{4}{|l|}{ Prochlorperazine } \\
\hline Sub-total & $29(100)$ & $52.0(33)$ & 100 \\
\hline $\begin{array}{l}\text { ncludes patients } \\
\text { ercent of the } \\
\text { escribed a parti } \\
1 \text { Pak Rs.) }\end{array}$ & $\begin{array}{l}\text { rescribed } \\
\text { patients } \\
\text { ar drug; }{ }^{\circ} \mathrm{C}\end{array}$ & $\begin{array}{l}\text { single anti } \\
\text { Group I } \\
\text { st in USD }\end{array}$ & $\begin{array}{l}\text { ychotic; } \\
\text { O were } \\
\text { USD = }\end{array}$ \\
\hline
\end{tabular}

Table 3 shows the drug prescription pattern and average annual drug cost for patients receiving antipsychotic polytherapy (Group II). This group represents $48.5 \%$ of the final population. In this group, oral risperidone and oral olanzapine was the mostly prescribed drug combination (32\%), followed by oral risperidone and LAI fluphenazine (24 \%). The mean cost of antipsychotic polytherapy was $\$ 103.20$ USD (Rs. 10427). The most expensive polytherapy treatment, a combination of oral risperidone and oral olanzapine, cost \$126.70 USD (Rs. 12797), or $39 \%$ of the mean polytherapy cost. 
Table 3: Types of antipsychotic used and annual drug cost for patients in Group II $^{\mathrm{a}}$

\begin{tabular}{|c|c|c|c|c|}
\hline Antipsychotic & Combination & n (\%) & $\begin{array}{l}\text { Average annual } \\
\text { cost }^{c} \text { (US\$, mean } \pm \\
\text { SD) }\end{array}$ & $\begin{array}{c}\text { Annual cost } \\
(\%)\end{array}$ \\
\hline $\begin{array}{l}\text { Two antipsychotics } \\
\text { Risperidone }+{ }^{a}\end{array}$ & $\begin{array}{l}\text { Olanzapine } \\
\text { LAl Fluphenazine } \\
\text { Quietipine } \\
\text { Aripiprazole }\end{array}$ & $\begin{array}{c}8(32) \\
6(24) \\
1(4) \\
1(4)\end{array}$ & $\begin{array}{c}126.7 \pm 54.6 \\
84 \pm 28 \\
141.3 \\
135\end{array}$ & $\begin{array}{c}39.3 \\
19.5 \\
5.5 \\
5.2\end{array}$ \\
\hline Olanzapine $+^{a}$ & $\begin{array}{l}\text { LAI Fluphenazine } \\
\text { Aripiprazole } \\
\text { Prochlorperazine }\end{array}$ & $\begin{array}{l}3(12) \\
416) \\
1(4)\end{array}$ & $\begin{array}{c}107 \pm 46.6 \\
91.2 \pm 12.3 \\
62.3\end{array}$ & $\begin{array}{c}12.5 \\
14.1 \\
2.4\end{array}$ \\
\hline $\begin{array}{l}\text { Haloperidol }+^{d} \\
\text { Subtotal }\end{array}$ & LAI Fluphenazine & $\begin{array}{c}1(40) \\
25(100)\end{array}$ & $\begin{array}{c}35.8 \\
103.2 \pm 43.9\end{array}$ & $\begin{array}{r}1.4 \\
100\end{array}$ \\
\hline
\end{tabular}

${ }^{a}$ Includes patients prescribed a combination of antipsychotics; ${ }^{1}$ Percent of the 25 patients in Group II prescribed a particular drug; ${ }^{\circ}$ Cost in USD; ${ }^{+}$indicate a combination of antidepressant drugs.

Table 4 shows the drug prescription pattern and average annual drug cost for patients who switched antipsychotic medications during the course of the study (Group III). Of the patients in this group, $22.2 \%$ switched from a combination of oral risperidone and LAl fluphenazine to oral risperidone alone, and $22.2 \%$ switched from a combination of oral olanzapine and LAI fluphenazine to a combination of oral olanzapine and oral haloperidol. Switching of other drug combinations occurred less frequently. The mean cost of antipsychotic therapy in patients who switched drugs was \$92.70 USD (Rs. 9366). The highest cost was incurred by patients initially treated with an oral risperidone and LAI fluphenazine combination who then switched to oral risperidone monotreatment. Treatment for these patients cost an average of $\$ 77.50$ USD
(Rs. 7836), about $18.6 \%$ of the antipsychotic cost for this group.

\section{Antipsychotic treatment patterns and cost analysis}

For the entire sample population, the mean annual cost of antipsychotics prescribed was US\$79.90 (Pakistani rupees (Rs.) 8079). For SGAs used alone, the mean annual cost was US\$ 80.29 (Rs. 8110). For FGAs used alone, the annual cost was \$25.20 USD (Rs. 2554). For a combination of SGAs and FGAs, the mean annual cost was US\$94.30 (Rs. 9528).

Post hoc LSD analysis using one-way ANOVA was used to assess whether various treatment regimens differed significantly in cost.

Table 4: Type of antipsychotic used and annual drug cost for patients in Group III

\begin{tabular}{|c|c|c|c|c|}
\hline Antipsychotic & Switch to & n (\%) & $\begin{array}{l}\text { Average cost }^{c} \\
(\text { mean } \pm \text { SD) }\end{array}$ & $\begin{array}{c}\text { Annual cost } \\
(\%)\end{array}$ \\
\hline Risperidone $+{ }^{\mathrm{d}}$ LAl Fluphenazine & Risperidone & $4(22.2)$ & $77.5(13.8)$ & 18.6 \\
\hline Olanzapine + LAI Fluphenazine & Olanzapine + Haloperidol & $4(22.2)$ & $65(18.7)$ & 15.6 \\
\hline Risperidone & $\begin{array}{l}\text { Risperidone + LAI } \\
\text { Fluphenazine }\end{array}$ & $1(5.6)$ & 64.3 & 3.9 \\
\hline $\begin{array}{l}\text { Risperidone + Olanzapine + LAI } \\
\text { Fluphenazine }\end{array}$ & Risperidone + Olanzapine & $1(5.6)$ & 148.8 & 8.9 \\
\hline Risperidone + Olanzapine & $\begin{array}{l}\text { Olanzapine + LAI } \\
\text { Fluphenazine }\end{array}$ & $1(5.6)$ & 241 & 14.4 \\
\hline Olanzapine & $\begin{array}{l}\text { Olanzapine + LAI } \\
\text { Fluphenazine }\end{array}$ & $1(5.6)$ & 106.6 & 6.4 \\
\hline Olanzapine + Haloperidol & Olanzapine & $1(5.6)$ & 78 & 4.7 \\
\hline Risperidone & Olanzapine & $1(5.6)$ & 172.2 & 10.3 \\
\hline Aripiprazole & Risperidone & $1(5.6)$ & 63 & 3.8 \\
\hline Olanzapine & Risperidone & $2(11.1)$ & $86(30.7)$ & 10.3 \\
\hline Olanzapine + Haloperidol & Haloperidol & $1(5.6)$ & 52 & 3.1 \\
\hline Sub Total & & $18(100)$ & $92.7(49.6)$ & 100 \\
\hline
\end{tabular}


All treatment regimens used by only one patient were excluded from this analysis. There was no statistically significant difference in the mean cost of the various antipsychotics used for monotherapy $[F(3,24)=1.9, p>0.05]$ or in the cost of various antipsychotics used for polytherapy $[F(3,17)=1.3, p>0.05]$. There was also no statistically significant difference in the mean cost of various antipsychotic drug treatments that were switched in the course of the study $[F(2,7)=0.8, p>0.05]$. However, a significant difference in treatment cost was observed for patients in group I compared with group II $(p<0.05)$ and for patients in group I compared with group III $(p<0.05)$. No statistically significant difference in treatment cost was observed for patients in group II compared with group III $[\mathrm{F}(2,69)=11.47, p<$ 0.05].

\section{DISCUSSION}

Antipsychotic monotherapy is recommended by most antipsychotic treatment guidelines $[9,10]$. In the present study, the percentage of patients receiving monotherapy was low compared with that in other countries $[7,10,11]$. The high incidence of polytherapy observed here may be due to the severity of symptoms; the patients from Sarhad Hospital for Psychiatrist Diseases who participated in this study were particularly unstable and may therefore have required more aggressive polytherapy treatment. Differences in study design may also account for the discrepancy in the number of patients receiving polytherapy. Tapp et al, for example, did not include drugs administered by LAI in the estimate of polytherapy treatment rates $[10,18]$. According to National Institute for Clinical Excellence, SGAs should be used as first-line antipsychotics in the treatment of schizophrenia. Clozapine, olanzapine, and risperidone are the most effacious and well tolerated SGAs in most schizophrenic patients. In our study, the majority of patients were prescribed SGAs. These results are consistent with the results from similar studies conducted in Australia, Bahrain, Germany, and the United States, where most schizophrenic patients were treated with SGAs $[7,10,11,19,20]$.

Our study indicates that the use of antipsychotic polytherapy is similar between Pakistan and Finland. Polytherapy is often used in the treatment of refractory schizophrenia. Polytherapy with FGAs and SGAs may be particularly effective because FGAs tend to act rapidly and may be able to quickly control psychotic symptoms until slower-acting SGAs become effective [10]. Polytherapy in which an
SGA is administered orally and an FGA is administered by LAl is often recommended for patients who resist treatment [21]. However, the literature suggests that patient non-compliance is mainly due to the belief that side effects associated with LAI are worse than side effects associated with oral therapy [13].

Polytherapy is also sometimes used early in treatment to manage the positive symptoms, and after these conditions are under control the patient is switched to SGA monotherapy. However a study conducted by Tapp et al [10] indicates that most psychiatrists found the FGA and SGA combination most effective and were therefore reluctant to switch from polytherapy to monotherapy. In this study, the rate of switching from one antipsychotic combination to another was $25 \%$. However, it is possible that some additional patients switched medications before the study began. The cost of SGAs in Pakistan is relatively low because most of the drugs are manufactured locally, although SGAs are still more expensive than FGAs [2,4,5]. Although SGA polytherapy, which typically combines an SGA and an FGA, can be considerably more expensive than monotherapy, the high cost of SGAs may be warranted, as it has been reported by Mauskopf and colleagues that treatment with SGAs reduces hospitalization and minimizes side effects, hence reducing overall medical cost and improving quality of life [22].

\section{Limitations of the Study}

The study enrolled only a small number of patients. However, in a developing country, conducting a 1-year follow-up study is challenging.

\section{CONCLUSION}

The present study assessed the economic cost of antipsychotics used in the treatment of schizophrenia in Pakistan. SGAs, which are the most frequently prescribed antipsychotic drugs, are costly compared to FGAs. The results of the present study can be used to assess the pharmacoeconomics of antipsychotic prescription practices and to afford policymakers with information necessary for developing successful pharmacotherapeutic plans for the treatment of schizophrenia.

\section{DECLARATIONS}

\section{Acknowledgement}

The authors are grateful to Dr. Abbas Ullah Jan, Professor of Economics, University of 
Agriculture, Peshawar, Pakistan for his input into the statistical and cost analysis.

\section{Conflict of interest}

No conflict of interest is associated with this work.

\section{Contribution of authors}

The authors declare that this work was done by the author(s) named in this article and all liabilities pertaining to claims relating to the content of this article will be borne by the authors.

\section{REFERENCES}

1. Siever LJ, Davis KL. The pathophysiology of schizophrenia disorders: perspectives from the spectrum. Am J Psychiatry 2004; 161: 398-413.

2. Suleiman TG, Ohaeri JU, Lawal RA, Haruna AY, Orija $O$. Financial cost of treating out-patients with schizophrenia in Nigeria. Br J Psychiatry 1997; 171: 364-368.

3. Shah ST, Sultan SM, Faisal M, Irfan M. Psychological distress among caregivers of patients with schizophrenia. J Ayub Med Coll Abbottabad 2013; 25: 27-30.

4. Farooq S, Burns J, Sumathipala A, Naeem F. A global mental health fund for serious mental illness in lowincome and middle-income countries. Lancet Psychiatry 2016; 3: 495-497.

5. Emsley RA, Oosthuizen PP, Joubert AF, Hawkridge SM, Stein DJ. Treatment of schizophrenia in low-income countries. Int J Neuropsychopharmacol 1999; 2: 321 325.

6. Kendall $T$. The rise and fall of the atypical antipsychotics. Br J Psychiatry 2011; 199: 266-268.

7. Weinbrenner S, Assion H-J, Stargardt T, Busse R, Juckel G, Gericke C. Drug prescription patterns in schizophrenia outpatients: analysis of data from a German health insurance fund. Pharmacopsychiatry 2009; 42: 66-71.

8. Menahem K. Weight gain, metabolic parameters, and the impact of race in aggressive inpatients randomized to double-blind clozapine, olanzapine or haloperidol. $J$ Schizophr Res 2009; 15: 95-102.

9. Faries D, Ascher-Svanum H, Zhu B, Correll C, Kane J. Antipsychotic monotherapy and polypharmacy in the naturalistic treatment of schizophrenia with atypical antipsychotics. BMC Psychiatry 2005; 5: 26.
10. Tapp A, Wood AE, Secrest L, Erdmann J, Cubberley L, Kilzieh N. Combination antipsychotic therapy in clinical practice. Psychiatr Serv 2003; 54: 55-59.

11. Al Khaja KA, Al-Haddad MK, Sequeira RP, Al-Offi AR. Antipsychotic and anticholinergic drug prescribing pattern in psychiatry: extent of evidence-based practice in Bahrain. Pharmacol Pharm 2012; 3: 409.

12. Rosenheck RA, Krystal JH, Lew R, Barnett PG, Fiore L, Valley $D$, Thwin SS, Vertrees JE, Liang MH. Long-acting risperidone and oral antipsychotics in unstable schizophrenia. N Engl J Med 2011; 364: 842-851.

13. Patel MX, Taylor M, David AS. Antipsychotic long-acting injections: mind the gap. Br J Psychiatry 2009; 195: S1S4.

14. Nazar Z, ul Haq MM, Rabbani F, Zahoor N, Awan NR. Symptomatic and general functioning in schizophrenic patients: Five years follow up at outpatient department. J Pak Psych Soc 2013; 10.

15. Bitter I, Chou J-Y, Ungvari G, Tang W, Xiang Z, Iwanami A, Gaszner $P$. Prescribing for inpatients with schizophrenia: an international multi-center comparative study. Pharmacopsychiatry 2003; 36: 143-149.

16. Williams JR. The Declaration of Helsinki and public health. Bulletin of the World Health Organization 2008; 86: $650-652$

17. Lwanga SK, Lemeshow S, Organization WH. Sample size determination in health studies: a practical manual. 1991.

18. Nazar Z, Rabbani F, Ali G, Zahoor N, Lawangeen S, Awan NR. Duration of illness, symptoms and functional recovery in patients suffering from schizophrenia. J Pak Psych Soc 2013; 10.

19. Keks NA, Altson K, Hope J, Krapivensky N, Culhane C, Tanaghow A, Doherty $P$, Bootle A. Use of antipsychosis and adjunctive medications by an inner urban community psychiatric service. Aust N Z J Psychiatry 1999; 33: 896-901.

20. Alam NN, Ara F, lqbal MJU. Prescribing pattern of psychotropic drugs used in non-psychiatric patients among outpatient department of two teaching hospitals in Bangladesh. Bangladesh J Pharmacol 2015; 10: 148151.

21. Farooq S, Nazar Z, Irfan M, Akhter J, Gul E, Irfan U, Naeem F. Schizophrenia medication adherence in a resource-poor setting: randomised controlled trial of supervised treatment in out-patients for schizophrenia (STOPS). Br J Psychiatry 2011; 199: 467-472.

22. Mauskopf J, Muroff M, Gibson PJ, Grainger DL. Estimating the costs and benefits of new drug therapies: atypical antipsychotic drugs for schizophrenia. Schizophr Bull 2002; 28: 619-635. 